\title{
Masters of our Destiny - The Integration of law clinic into post graduate Masters provision
}

\section{Karen Clubb*}

Increasingly students are looking to their undergraduate law degrees to do more than provide them with a qualification which acts a 'stepping stone' to further legal vocational training. The provision of law degrees across the sector includes both qualifying and non-qualifying degrees where the study of law is combined with other subjects, vocational and non-vocational. Not all students who obtain a qualifying law degree will continue to the vocational stage of training, ${ }^{1}$ but all degrees need to address the employability agenda, and law students in particular need to consider future career aspirations early on in their degree.

Clinical legal education as a teaching methodology has received considerable academic attention for the benefits student engagement can yield in enhancing the overall student learning experience. This paper briefly reviews the benefits of undergraduate clinical legal education (CLE) and considers the benefits of developing this at post graduate level in a Masters in Law programme. This paper considers the distinction between the two approaches and the need for a different approach to the provision of a law clinic module within a postgraduate law Masters programme, identifying a possible model of delivery.

The paper further presents some of the potential challenges in developing and maintaining this provision over time and attempts to offer some insight into how these have been considered in the development of a postgraduate law clinic module at the University of Derby.

\section{Clinical Legal Education - undergraduate experience}

In the last ten years there has been a significant increase in the integration of Clinical Legal Education (CLE) into the undergraduate law curriculum. ${ }^{2}$ The definitions of CLE are broad and include participation of students in legal service provision as well as the use of simulated exercises and tasks. The definition of CLE offered by Grimes defines CLE as:

* Senior Lecturer in Law, University of Derby

1 Cole Strategic Research Unit 'Trends in the Solicitors Profession Annual Statistical Report 2006'

2 Grimes R., Brayne H., 'Mapping best practice in clinical legal education' UKCLE October 2004, para 3.6 
a learning environment where students identify, research and apply knowledge in a setting which replicates, at least in part, the world where it is practised... It almost inevitably means that the student takes on some aspect of a case and conducts this as it would... be conducted in the real world. ${ }^{3}$

Other definitions seek to capture the pedagogic approach:

exposure to real or realistic situations in which the student is required to address legal and related matters, taking responsibility (individually or collectively) for the resolution of problems and the associated tasks; coupled with the opportunity for reflection on issues, means of resolution and task performance, as an integral and structured part of a course of study. ${ }^{4}$

The provision of CLE across the sector is varied as are the models of practice supporting this experiential learning provision which promotes student learning by participation in the provision of some aspect of legal service/work. ${ }^{5}$ Only a few institutions are able to offer integrated in house law clinics and the experience of 'live client work', ${ }^{6}$ other institutions rely on community projects, often termed 'street law,' as the basis of CLE. Although CLE is valued as an experiential learning model it is not currently a mandatory requirement of qualifying law degrees in England and Wales. ${ }^{7}$ The Joint Academic Stage Board (JASB) do not stipulate any particular teaching and learning methodologies, these are left for determination by the institutional providers. ${ }^{8}$ This is also the case with the Legal Practice Course (LPC), which whilst specifying the minimum contact and teaching hours for core subjects, and stages of study, does not mandate that the learning be derived from participation in a work based learning environment and professional practice. ${ }^{9}$

Although CLE is not mandated as a component of a qualifying law degree, its inclusion in the undergraduate curriculum was considered by the ACLEC report as far back as 1996. This highlighted the need for provision of a "broad and intellectually demanding legal education" which it regarded as "fundamental to our commitment to constitutionalism and an extension of the rule of law." It identified the need for an awareness of the "ethical and humanitarian dimensions of the law as an instrument which affects the quality of life," recognising what it saw as the fundamental democratic value of the law, and of the need to impart and preserve the common core professional values and skills. The report clearly recommended as a vision for the future, a reduced demarcation between the academic and professional stages of training, integrating and instilling a commitment to "the rule of law, justice, fairness, and high ethical standards." 10 For institutional providers the

3 Grimes R., 'The Theory And Practice Of Clinical Legal Education' in J. Webb and C.Maugham (eds.) Teaching Lawyers' Skills (1996) at p 138.

4 Browne S. (2001) A survey of Pro Bono Activity By Students In law Schools in England and Wales Law Teacher Vol 35 pt 33, at 34 .

5 Plowden P., 'Model standards for live-client clinics' Clinical Legal Education Organisation (CLEO) 1995.

6 Marson J., Wislon A, M Van Hoorebeek., 'The Necessity of Clinical Legal Education in University Law Schools: A UK Perspective.' Available at http://www.northumbria.ac.uk/sd/academic/law/entunit/norlawpress/ jour/IJCLE_2/IJCLE_Aug05/6633812/ Date Accessed 26/06/2012

7 Joint Academic Stage Board Handbook, September 2011, Appendix M.

8 Joint Academic Stage Board Handbook, September 2011, para 2.2

9 SRA' Information for the provider of Legal Practice Courses', Education and Training Unit, May 2012. Available at http://www.sra.org.uk/lpc/

10 The Lord Chancellor's Advisory Committee on Legal Education and Conduct, 'The First Report on Legal Education and Training'(ACLEC) London 1996, paras 1, 1.14, 1.15, 1.19 
provision of CLE enables these values to be promoted in a way that is meaningful and derived from real and personal experience and participation of students in a work based and professional context facilitating the development of skills and values relevant to and necessary for professional practice.

Since the ACLEC report there has been a greater integration of CLE into undergraduate curriculum and the provision of law clinics and to a limited extent there has some movement towards the merger of the academic and vocational stage. Some institutions now offer integrated pathways of study that combine undergraduate and vocational stages of study. However the changes in the funding of higher education render the 'employability' agenda a more critical consideration regardless of whether students go onto the later vocational stage of legal training or take the route of further postgraduate study of law. Equally postgraduate provision also requires students to have 'an eye' on the employment context to convert their enhanced academic study into clear transferable skills that are relevant and valuable to future employers and to demonstrate they are in touch with the employment context in which theses skills will be delivered.

\section{The Experiential Learning Model}

The integration of CLE and experiential learning at undergraduate level remains firmly grounded in addressing the educational goals relevant to this academic stage of study. ${ }^{11}$ The engagement within a work-based learning context affords students the opportunity to develop their knowledge of the substantive law alongside their knowledge of the relevant legal processes, as well as developing generic and transferable skills under supervision, equally relevant to those students focused on careers outside law. ${ }^{12}$ Experiential learning is recognised as promoting more effective, deeper and contextualised learning, promoting insight into the professional values, and can illuminate as to the impact of 'policy' and the concepts of what some term 'social justice issues'. ${ }^{13}$ Students are also able to develop an understanding of the commercial context and pressures relating to the delivery and operation of legal services.

The experiential learning associated with CLE is highly motivating and rewarding for learners, ${ }^{14}$ taking them beyond the classroom where learning from 'action' is rooted in 'real life' situations. It also affords students the chance to see the tangible benefits to their contribution to both individuals and the community. Each learning experience remains unique with students taking a greater role and responsibility for their participation and reflection on their learning, preparing them for the ethos of continuing professional/ skills development. ${ }^{15}$

In the academic environment the context of theory and practice - legal knowledge and participation in the legal process are more often divorced from each other or limited to specific simulated skills, tasks or problem orientated assessment involving other students. Experiential 'law clinics' places

11 Plowden P., 'Model standards for live-client clinics' Clinical Legal Education Organisation (CLEO) 1995, See Appendix 4 for suggested learning outcomes.

12 The Lord Chancellor's Advisory Committee on Legal Education and Conduct, 'The First Report on Legal Education and Training'(ACLEC) London 1996, para 1.11.

13 Plowden P., 'Model standards for live-client clinics' Clinical Legal Education Organisation (CLEO) 1995, para $1.1-1.4$

14 Cruess R.L., Cruess S.R. 'Teaching Professionalism: General Principles' Medical Teacher Vol 28(3) (2006) $205-$ 208

15 Rees C., Forbes P., Kulber B., 'Student Employability Profiles A Guide for Higher Education Practitioners HEA ( September2006) 
learning in a realistic, genuine and dynamic context offering potentially rich insights into the legal values and norms.

The reflective process, which accompanies the experiential learning model ${ }^{16}$ ensures that students are more highly attenuated to the learning process and their learning needs. Experiential learning can be instrumental in offering clarity on future career options. Additionally students are further motivated by the perceived value in the engagement with services which have an impact on and offer a value and contribution to the wider community.

Given the advantages of experiential learning in the context of CLE at undergraduate level, the need for students to develop transferable work skills linked to the attainment of generic and subject specific graduate profiles; one wonders why this has not been more readily replicated in postgraduate Masters programmes in law.

\section{Postgraduate Masters Clinic}

Masters level study is a distinctly different educational provision from undergraduate legal studies, not least as postgraduate law students at Masters level may not in every case have an undergraduate law degree, and may indeed have a law degree from a different jurisdiction. For some students their work experience and employment history may secure entry to the programme. Masters level provision is a more intensive time constrained pathway of study, demanding a greater degree of learner autonomy and critical reflection. Postgraduate study is undertaken with a view to developing niche areas of knowledge and expertise in a distinct and specific programme of study offering intellectual challenge. Increasingly programme selection is made in light of anticipated future career pathways and employment opportunities.

Masters study aims to develop advanced research skills through engagement with a critical analysis and examination of substantive areas of law and theoretical and doctrinal approaches to the selected area. At Masters level this requires further consideration of contemporary and emerging approaches to the relevant legal issues as well are a more detailed critique of their rationale and effectiveness. Students are expected to demonstrate a greater degree of originality in their work in preparation for possible further doctrinal study. A crucial feature of Masters level study is the examination of both the substantive and procedural aspects of the law, and a wider consideration of the socio-economic and political context in which the critical legal issues are situated. Students need to draw extensively on academic discourse, empirical research and normative approaches requiring consideration of issues beyond domestic jurisdiction, drawing on the international context and comparative approaches.

Generic transferable skills relate to the advanced research undertaken and the degree of independent learning accompanied by the ability to critically reflect on a wide range of concerns and conceptualisation of doctrinal and theoretical models to communicate effectively the key issues, propose solutions, and present research findings.

For law clinic to be applicable at postgraduate level given the nature and focus of study, the context in which current undergraduate law clinic experiential learning is offered may not yield appropriate opportunities to facilitate the depth of research and critical reflection commensurate with this

16 Clubb., K. 'Using Reflection to Enhance Work-Based Learning: Towards Professionalism' Lili Conference Warwick (2008). 
stage of study. The experiential model of learning by doing offers a narrow range of activities and opportunity for practical skills (interviewing, letter writing, drafting) for student engagement under supervision which do not match the required research skills focus relevant to postgraduate study.

An important consideration for all undergraduate CLE experiential law clinics is that participating students actively contribute to service delivery, delivering a tangible benefit. This is crucial for institutions such as the University of Derby that rely on a placement provider type model of provision and is a relevant consideration in developing a clinic module at postgraduate level. At postgraduate level the student process of participation may vary but the clinic experience still needs to deliver benefits for the students and the legal service/ provider. For postgraduate clinic provision the opportunity for experiential learning needs to relate to some form of research activity and service audit. The participation in these areas still requires participation in practical tasks, such as interviewing, and competency in generic skills providing the platform for participation and student engagement.

The needs of postgraduate students regarding law clinic provision are very different calling into question the appropriateness and viability of the conception of law clinic at undergraduate level and the experiential model which underpins this. The narrow experiential context (professional practice) and practical tasks undertaken by students in undergraduate law clinics are not likely to deliver limited opportunities for reflection and identification of research opportunities relevant to postgraduate legal study. Indeed the service provision in which the experiential law clinics are based may preclude the resources, time and support needed to meet postgraduate student needs in practice.

The starting point is to attempt to capture the benefits of learning in the context which experiential learning affords within a model or approach that defines the relevant context for postgraduate law clinic and the process of learning and learning goals. The model adopted will then inform as to the appropriate selection of the relevant learning contexts and the selection of appropriate partner providers.

Whatever the model of postgraduate provision selected, employability remains as crucial as to the undergraduate experience, as does the need to 'integrate doctrinal knowledge with a fuller clinical experience throughout the student journey'. ${ }^{17}$

Postgraduate clinic provision can capitalise on the knowledge that students learn most effectively when their learning is context driven, related to current issues and challenges and supported by the knowledge of experts and those with experience in the field. To this end aspects of 'practice' as a form of CLE are already incorporated in the postgraduate curriculum by integrating the contributions of practitioners and researchers into module delivery. This offers a 'more intensive, mutual and fruitful partnership which should ultimately break down the distinction between clinical and traditional teaching sessions.' 18 The clinic module merely shifts the focus and balance of these elements and the context from CLE in the classroom to a work based context which offers a richer and broader learning experience that is potentially more meaningful. ${ }^{19}$

17 Hall J., Kerrigan K., 'Clinic and the Wider Law Curriculum' 16 Int'l J. Clinical Legal Educ (2011) $25,25$.

18 Hall J., Kerrigan K., 'Clinic and the Wider Law Curriculum’ 16 Int'l J. Clinical Legal Educ (2011) 25,30

19 Hall J., Kerrigan K., 'Clinic and the Wider Law Curriculum' 16 Int'l J. Clinical Legal Educ (2011) 25,34 


\section{A possible model of delivery - 'Action research'}

The author proposes consideration of an action research type model as a basis for the provision of postgraduate law clinic. This has history of use and application in the context of education and business by practitioners to examine and audit the effectiveness of service provision and the methodology of practice and its effectiveness. The aim of action research has been to seek to critically evaluate an aspect of professional practice to offer further insights and improvements on both the context of an identified area of professional practice and the service area in which it is located. The action research model goes beyond the immediate skills focus as to what is done and how, by seeking to critically evaluate the rationale for the practice and its effective application. The model merges both practice and theory and in so doing requires a more holistic consideration of the relevant professional and service context and its underlying values. The experiential model is highly dependent on the quality of the student's 'practical performance' to determine the overall learning experience in terms of the opportunity for participation and observation by the students to facilitate learning. The action research model requires access to the identified professional or service context to 'trigger' the identification of the research project and the identification and problematization of critical issues. The student's participation in the subsequent research project / process yields a potential end gain for the service and the student, whilst simultaneously offering the capacity to reconstruct the role of the student in their clinic experience, to one which compliments and support the attainment of postgraduate Masters level learning outcomes.

The action research model is traditionally associated with being a stimulus for organisational change and is based on the concept of collaborative team working to bring together a critical investigation of theory and practice through critical reflection and the application of selected research methodology. The approach is both reactive to the current position and practice as well as proactive in seeking to investigate and to further inform change. As a model of practice for postgraduate law clinics, it allows flexible accommodation of critical reflection on current legal issues, and can readily accommodate 'objective and naturalistic forms of enquiry.' 20 The model aligns well with the increasing trend to forge links between the academic community and Higher Education Institution's, public bodies and legal service sector. The latter have the expert knowledge of the law in practice and the former the experience and expertise in research necessary to investigate and scrutinise the value of aspects of practice or service provision. The model aligns theory and practice $^{21}$ in particular to address the wider context in which the law operates, comparatively and beyond national borders addressing 'matters such as legal theory, interdisciplinary team working, ethics, issues of internationalisation, and culture and gender', as appropriate. ${ }^{22}$

Additionally the identified features of action research identified by Stringer as 'change, reflection, participation, inclusion, sharing, understanding, repetition, practice, community' are relevant generically to the employment, context, where team working and a participatory and inclusive approach to project management and research are essential. ${ }^{23}$ The action research approach offers

20 Stringer E., Action research in Education (2nd Edn Pearson Press 2008), 10.

21 Trehan K., Pedler M., 'Research and evaluation in assessing outcomes and impacts in action learning' Action Learning: Research and Practice, 7(1) (2010) 1, 1.

22 Mackinnon J, 'Problem Based Learning and New Zealand Legal Education 3 Web JCLI [2006] at 13 <http://webjcli.ncl.ac.uk/2006/issue3/mackinnon3.html> Date Accessed 20/06/2012

23 Stringer E., Action research in Education (2nd Edn Pearson Press 2008), 33. 
flexibility in selection of research methodology and allows for the merging of a consideration of the legal issues with the context of service delivery, organisational structure, strategic decision making, offering insights into professional values within a 'community' context. The action research framework allows for scrutiny of existing practice to find a more positive solution and improved legal and wider service responses to client need and the presenting legal issues. ${ }^{24}$ It also affords the opportunity for students to demonstrate leadership skills in the implementation of the team research and project management. The aim is for students to work in partnership with the clinic partner, without acting as consultants, to ensure that the research is meaningful and appropriate to the creation of relevant knowledge and originality and delivers meaningful outcomes for the clinic partner.

What is critical for postgraduate study is that research derived from a practice setting allows for the development of originality of thought to provide a theoretical frame work to pragmatic external processes that may drive behaviour. ${ }^{25}$ The action theory model also creates possibilities for the development of theory from practice but additionally shares characteristics with problem based learning, since some of the solutions sought are derived from and are driven by the need to seek resolutions to a particular process, practice concern or problem. ${ }^{26}$

\section{Pedagogic advantages of action research model}

From a pedagogic perspective the action research approach has much to offer. Research indicates ${ }^{27}$ that this promotes deeper learning across all phases of the action research process with learners better placed to resolve service/ legal problems, dilemmas. Further, learners gain a deeper understanding of the learning process linked to on-going critical reflection and continuous deeper rather than episodic learning. The problem based and reflective elements of this model require reflective participants; 'those who are sufficiently conceptually literate to read and critique key aspects of the social order and to understand their own and others' status and role, ${ }^{28}$ an essential skill for team work and project management. Continuous learning and development are crucial to continuous professional development, relevant to both academic and legal practice alike.

The offering of a law clinic experience at Masters level offers the opportunity to bring alive the rather dry area of legal research methodology by providing a realistic context in which these skills can be learnt, applied and developed. Rather than considering hypothetical situations at a distance, students are immersed in a real life context where they have to conceive a research project, design and design, critique and implement this in partnership with external agencies/ bodies. The work based context allows undertaking of data collection and analysis, production of research reports

24 Takis Karallis \& Eric Sandelands (2011): Building better futures: leveraging action learning at Kentz Engineers \& Constructors, Action Learning: Research and Practice, 8:1, 57-64. The authors here presented learning linked to the corporate context in finding new business solutions and to enable better responses to customer need.

25 Takis Karallis \& Eric Sandelands (2011): Building better futures: leveraging action learning at Kentz Engineers $\&$ Constructors, Action Learning: Research and Practice, 8:1, 57, 63

26 Mackinnon J, 'Problem Based Learning and New Zealand Legal Education 3 Web JCLI [2006] <http://webjcli.ncl.ac.uk/2006/issue3/mackinnon3.html> Date Accessed 20/06/2012

27 Skipton Leonard H., and Marquardt M.J., Action Learning: Research and Practice Vol. 7, No. 2, July 2010, 121,126 . Here the authors cite the research of Von Schuyver 92004) on this issue.

28 Mackinnon J, 'Problem Based Learning and New Zealand Legal Education 3 Web JCLI [2006] at 18 <http://webjcli.ncl.ac.uk/2006/issue3/mackinnon3.html > Date Accessed 20/06/2012 
within time constraints, demonstrating an on-going sensitivity and consideration of the relevant ethical, social, policy and context and constraints of the partner institution service delivery.

Further the experience places student in a better position in terms of up skilling them for future Doctoral studies and places the advanced research that may have intimidated many within reach of their academic progression. Students who engage in research that has a worthwhile impact within the dynamics of live research environments connected to service provision are more likely to be enthused and motivated to further Doctoral research and study. They are also more confident and better placed in terms of their skills development to pursue this or to transfer these skills to an employment arena.

\section{Practical considerations}

Students undertaking a law clinic experience do so for their own personal and academic development, whether the provision is assessed or not. Provision at undergraduate level may serve to boost the student CV, may be voluntary and non-assessed. At Masters level this law clinic provision is likely and arguably should always form an assessed part of the student programme of study, if the action research and the partnership model advocated in this paper is followed.

The selection of projects and placements requires careful consideration and negotiation to ensure that the clinic provision at postgraduate level secures a student experience tailored to meet the learning outcomes of postgraduate study. The implementation of the action research model will require scrutiny of client files, access to documentary evidence from a placement provider, and may involve interviews of service users and staff team. These activities require a robust protocol for the management of the research process and associated ethical issues arising. This will apply to the research design and methodology and ethics approval processes required by the academic institution and the provider, but additionally to the implementation and management of these throughout the life of the project which is the basis of the clinic provision. A close partnership is required between the higher education institution and the providers to secure and manage this throughout.

As with undergraduate provision the challenge associated with this kind of experience is in firstly securing the placement opportunities that align with meeting the demands of postgraduate study. This proactive process may entail partnership projects involving a number of students at any one time, where the project operates over a longer period than the individual student placement and modular assessment. Students may make an active contribution by engagement with the research projects, completing reflective reports on their learning and contribution, adducing work to evidence this. Additionally as with undergraduate provision clear protocols need to be in place to oversee arrangements and clarify areas of responsibility and the degree of supervision and support needed by both the student and the partner provider. Students also need an induction process, ${ }^{29}$ which may include a determination of the student's skills level, written and oral communication, interview technique, research skills, to ensure students are adequately positioned to be able to gain from the placement and function effectively whilst doing so.

29 Plowden P., 'Model standards for live-client clinics' Clinical Legal Education Organisation (CLEO) 1995.para 20.1.1. 


\section{Our Approach}

The distinction between undergraduate and postgraduate clinic is exemplified in a number of ways, not least the different learning outcomes. At Masters level these require students to demonstrate an understanding and critical evaluation of the theoretical concepts and frameworks relating to a professional/ legal practice, reflection and research on a substantive area of law / aspect of the law or legal process or service relevant to the context of their overall pathway of study at postgraduate level. The learning outcomes contextualise the approach to learning and the focus and distinction of postgraduate study to ensure that the criticality and research are linked to a furthering of student knowledge and relevant to the focus of their postgraduate study. This is balanced with the needs of the partner providers and their conceptualisation of the issue which forms the focus of the postgraduate clinic research/ activity.

The experience of law students to date has been to engage in live court observation with a view to developing a formal research project in conjunction with partner providers, still at the stages of inception. Students undertook a comprehensive literature review and through discussion with practitioners and academics identified possible areas of research. As a research activity, students also had to present an outline title and research proposal which they submitted for ethics approval. This required students to select an appropriate methodology and to consider the application and viability of this in practice. Additionally students selected an appropriate area of substantive law and through observation of legal proceedings together with further reflection and research of specific aspects of legal process and procedure, considered comparatively with other jurisdictions and where appropriate, the international context.

Students were offered regular support and opportunities for formative feedback on the progression of their clinic experience and importantly clear guidance on the expected standards of academic engagement required for postgraduate level study.

The response from students was positive in that they felt able to apply in practice what they had learnt in their core legal scholarship modules in the context of delivery of legal services affording them a greater appreciation of the context and the relevant ethical issues. Students can readily adopt a comparative element in their research, benefitting home, EU and international students thus promoting inclusion. The module was particularly instructive in merging practical observation which stimulated reflection and curiosity, comparison and a critical and questioning approach. This then motivated students to research identified areas with interest and enthusiasm derived from real factual contexts. Students became aware that research is a natural, rather than separate, feature of reviewing service delivery and the substantive law and legal process in practice. The module brought alive the classroom based research activities which can often seem divorced from context and lack the interest that situated observation of 'real life cases' and proceedings deliver.

\section{Conclusion}

For the future it is envisaged that partnerships will be developed with external organisations, such as the Crown Prosecution Service, local authorities and charitable organisations, to develop and support their outreach work, undertake research related to an aspect of their function or service delivery, or aspect of service audit. This may include research that focuses on the impact of their service to their clients, for example relating to an aspect of victim participation or victim impact in the criminal justice process. Alternatively this could also involve research related to the legislative 
framework relating to the exercise of a legal duty or function by the stakeholder partner and a review of the model of practice and decision making process and factors impacting on this.

Whatever the core research activity and project forming the basis of the student participation, this will require a sensitive balancing and positioning of service and student needs and expectations, to ensure all are adequately met. The structure of the Masters clinic provision presented, offers clear advantages in placing learning in the context of professional practice and service delivery, providing a valuable source of 'real world' learning and engagement. This context has the potential to enthuse and motivate students, adding to the quality of their student learning experience. A note of caution does however need to be sounded, At postgraduate level the period of study is arguably more advanced and intensive, and operates within a shorter time frame. Students come from more varied backgrounds, with different learning experiences and cultural sensitivities. The organisation of the clinic module and the support integrated into this at induction and on-going, may prove more critical at Masters level for the partner organisation as well as for the students. The management of the law clinic placement is arguably high risk for all involved, since postgraduate level learners are expected to operate with a significant degree of autonomy. This raises a different set of a concerns for clinic at Masters level, given the commercial sensitivity and confidentiality pertaining to the provider's processes and data, necessitating clear guidelines to students and robust protocols to manage the central research activity and the clinic opportunity.

This paper has considered some of the similarities in the provision of law clinic experiences as a form of CLE at undergraduate and postgraduate level, and has sought to highlight the differences and distinction between the two forms of provision. These differences justify the adoption of a different model of development and implementation of the postgraduate law 'clinic' experience. The action research model as a starting point, most closely aligns with the aims and expectations of postgraduate legal education and partner providers and capacity to support this.

Whilst some have considered the wider integration of CLE across the whole of the undergraduate curriculum, ${ }^{30}$ this is not so essential at Masters level. The focus of study is more conceptual than skills based, and students by the nature of their studies are expected to consider issues holistically and comparatively more readily addressing the contextualisation of the law in practice, which is the key impetus at postgraduate level. ${ }^{31}$ The integration of CLE at Masters level across the programme is however satisfied by inclusion of the perspective of 'experts' and those with 'experience' in appropriate settings, who can bring a unique perspective to the relevant issues. The greater focus on research informed teaching also supports this approach. This prevents reliance on the postgraduate clinic experience as the sole form of CLE, since it is prone to becoming 'hostage' to the on-going support of external organisations, whose priorities and commitments may not secure on-going and long term postgraduate clinic provision with the same provider. ${ }^{32}$

30 Hall J., Kerrigan K., 'Clinic and the Wider Law Curriculum' 16 Int'l J. Clinical Legal Education (2011) 25,29. the authors here considered the wider application of CLE into the undergraduate law curriculum but did not advocate this stating 'We do not advocate that students learn from clinical problems exclusively. Simply thatthey sometimes do'

31 Grimes R., Brayne H., 'Mapping best practice in clinical legal education' UKCLE October 2004, para 3.3.2

32 Grimes R., Brayne H., 'Mapping best practice in clinical legal education' UKCLE October 2004, para 3.5 